\title{
Conceito de Gestão do Desporto. Novos desafios, diferentes soluções
}

\author{
Gustavo Manuel Vaz da Silva Pires \\ Faculdade de Motricidade Humana, \\ Universidade Técnica de Lisboa
}

https://doi.org/10.5628/rpcd.01.01.88
José Pedro Sarmento de Rebocho Lopes Faculdade de Ciências do Desporto e de Educação Física, Universidade do Porto

\section{APRESENTAÇÃO}

Se atendermos às posições dos diversos autores, Costa, L. (1979), Parkhouse, L., \& Ulrich, O. (1979) Chazaud, P. ( 1983) Chelladurai, P. (1985, 1994), Gordon, A. (1988) Tatarelli, G. ( 1986), Zeigler, E. (1987), Parkhouse, B. (1996) Slack, T. (1991, 1998), Soucie, D. (1994) Pires, G. \& Claudino, R. (1994), entre outros, que nos últimos vinte anos se têm dedicado à problemática da Gestão do Desporto, podemos encontrar um conjunto de indicadores que determinam a sua existência como uma nova área de intervenção profissional. De facto, ao sistematizarmos os aspectos mais significativos, podemos desenhar esta nova área de conhecimento tendo em atenção um conjunto de seis ideias que passamos a indicar. Em primeiro lugar, o estado de crise do desporto moderno que determina a necessidade de existirem novas mentalidades no que respeita ao desenvolvimento. Em segundo lugar, a complexificação das práticas desportivas que obriga a uma sistematização das teorias da gestão contextualizadas ao mundo do desporto. Em terceiro lugar, o surgimento de várias organizações relacionadas das mais diversas maneiras, com a gestão do desporto, o que permite a institucionalização não só duma área do conhecimento como, também, de intervenção profissional. A existência de investigação científica na área é o quarto aspecto determinante para o desenvolvimento da Gestão do Desporto. Em quinto lugar, as oportunidades profissionais que estão a surgir num mundo em que os empregos interessantes estão a rarear, demonstram que estamos em presença duma dinâmica de afirmação no quadro das oportunidades de emprego para as novas gerações. Em sexto, a formação inicial de nível superior no âmbito da Gestão do Desporto parece-nos ser uma realidade que vai garantir a nível do sistema a existência duma forte pressão provocada pelas novas gerações acabadas de sair das universidades. Neste trabalho vamos desenvolver cada uma das ideias atrás expressas de forma a avançarmos para aquilo que consideramos ser o enquadramento institucional da Gestão do Desporto para, de seguida, apresentarmos algumas conclusões e oportunidades futuras.

\section{CRISE DO DESPORTO MODERNO}

A crise do desporto moderno parece-nos ser um dos indicadores mais significativos que nos aconselham a reequacionar os modelos tradicionais de organização desportiva. Tanto o "desporto profissional" como o "desporto educação" estão em profunda crise. Esta crise surge também da desagregação do modelo corporativo do desporto tradicional, que já não responde às dinâmicas da sociedade da nova economia naquilo que esta tem a ver com a industria do entretenimento associada às novas tecnologias de informação e comunicação e ao desporto.

No desporto, sempre foi mais importante "fazer" do que "saber fazer", ou mesmo até "porque é que se fazia de determinada maneira". O "just do it" da NIKE, representa bem uma atitude que conduziu à maior crise do desporto moderno, que surgiu nos media em inícios de 1999 mas que vai persistir nos próximos anos. Como se sabe, esta crise teve como protagonista mais visível o Comité Internacional Olímpico que se viu envolvido em processos de corrupção relacionados com a escolha das cidades organizadoras dos Jogos. O falso amadorismo dos dirigentes tem de dar lugar a um sistema claro em 
que o próprio Olimpismo, como património da Humanidade, possa continuar a ter algum sentido para a generalidade das pessoas, por esse mundo fora. Actualmente, a projecção do desporto na sociedade, obriga a outras estratégias, atitudes e procedimentos, no que concerne ao seu próprio desenvolvimento. Por isso, em matéria de desporto, já não chega só "fazer", é necessário saber "porquê?" para depois se decidir "como" se vai realizar e "qual" a melhor maneira possível de o conseguir, sob pena de, se tudo for deixado ao acaso, o desporto poder vir a transformar-se num mero espectáculo circense gerido por pessoas sem ideias e sem projectos para além dos seus interesses pessoais, e alimentado, em muitas circunstâncias, por massas alienadas pela violência da competição ou por regionalismos exacerbados, que atrairão invariavelmente para as suas causas, políticos e empresários que vão, da pior maneira, aproveitar-se do desporto. Quer isto dizer que, não é qualquer prática que interessa quando se trata de teorizar a Gestão do Desporto. A prática tem de ser susceptível de teorização e isto só é possível se for reflexiva e crítica, porque senão não passa duma mera repetição.

Neste quadro de ideias, a Gestão do Desporto pode justificar-se em duas perspectivas. Na primeira, a que podemos designar de pragmática, a Gestão do Desporto existe porque tem soluções para resolver problemas, quer dizer, estamos perante uma Gestão do Desporto do tipo "chaves na mão". Trata-se de gerir rotinas. Toda e qualquer organização tem rotinas para processar e quanto melhor elas forem realizadas mais a organização está disponível para idealizar e desenvolver novos projectos. Noutra perspectiva, a que podemos designar de académica, a Gestão do Desporto também tem razão de existir porque há ou surgem problemas imprevisíveis para os quais é necessário encontrar respostas originais. Para o efeito, utiliza-se aquilo a que se convencionou chamar de funções da gestão ou tarefas do gestor. Nesta segunda perspectiva, estamos perante um sistema em que as soluções são encontradas pela capacidade heurística de construir o algoritmo conducente à solução de determinado problema. É o que se espera dos licenciados ao serem capazes de formular perguntas, problematizar as questões, sistematizar as possíveis soluções e escolher a mais ajustada.
Hoje, o estado de crise, tanto do "desporto profissional" como do "desporto educação" aconselham a que sem descurar os mecanismos normalizados da primeira perspectiva, se aposte também na Gestão do Desporto enquanto instrumento capaz de resolver ou, pelo menos, ajudar a resolver, os estigmas do desporto moderno. Uma coisa parece-nos evidente. É que se continuarmos a utilizar as mesmas soluções para os problemas que existem, não podemos esperar obter resultados muito diferentes daqueles que já foram obtidos no passado. Do mesmo modo, quernos parecer que não são as pessoas que estão há oito, dez, doze dezasseis e mais anos nos vértices estratégicos das organizações desportivas que vão mudar seja o que for, por muito que elas apregoem a necessidade de mudar mentalidades.

De facto, em nossa opinião, há que transformar a crise do desporto moderno numa oportunidade para as novas gerações, com as mais diversas formações, em busca dum emprego e da consequente realização pessoal e profissional, num mundo, como se disse, em que os empregos interessantes estão a rarear.

\section{COMPLEXIFICAÇÃO DA GESTÃO}

No que diz respeito ao terceiro aspecto, salta à vista que, nos últimos anos a gestão tem vindo a complexificar-se. A teoria da gestão em geral tem vindo a desenvolver-se obrigando a um esforço complementar aqueles que, no mundo do desporto, querem acompanhar a evolução. Esta complexificação fica, obviamente, a dever-se, à própria complexidade da dinâmica social. A Gestão do Desporto não fugiu a esta regra, tanto na América do Norte como na Europa, pelo que não só a investigação como o próprio ensino têm evoluído duma abordagem pragmática dos problemas para uma perspectiva filosófica e, por isso, teórica dos mesmos. No entanto é bom que se entenda que se a prática só por si não passa duma mera repetição, por outro lado, qualquer teoria que não seja cruzada com a realidade prática, não passa dum simples acto de contemplação. De facto, a teoria para valer alguma coisa, terá sempre de ser testada pela realidade prática.

Vamos analisar este capítulo tendo em atenção três realidades distintas. Em primeiro a norte-americana. Em segundo a europeia. Em terceiro a portuguesa. Finalmente fazemos uma síntese do capítulo. 


\subsection{América do Norte}

Na América do Norte a Gestão do Desporto pode ser analisada a partir das ligas profissionais, por um lado, e o sistema de competição inter colégios e universidades por outro. Em qualquer das situações, todo o sistema desenvolveu-se com uma lógica de negócio. Para Calhoun (1981)"the history of sport is the story of transition from amateurism to professionalism." No que diz respeito às ligas de acordo com Gallant (1991:122) o seu surgimento aconteceu em 1869 com o baseball: "Organized professional sports leagues in the United States began in 1876, when baseball's National League was formed. Several of its guiding principles have continued throughout the subsequence development of professional sports in this country. Individual clubes began by cooperating with each other regarding the market supply of producers and consumers. The producers were the players, who made the product by playing the games on the field, and the consumers were the fans, whose ticket purchases provided operating expenses and profits." "Individual clubs within a professional sports league are nominally independent legal entities, free to make or lose money depending upon how they operate their businesses." "therefore each member club must be considered as both a private business entity, and a franchise, operated in accordance with the league-wide concerns." A gestão territorial das ligas é realizada numa base de "conquista de monopólio, sem, contudo interferir com o sistema de competição inter colégios e universidades. As competições no âmbito dos colégios e universidades arrancaram sob os auspícios do Presidente Theodore Roosevelt em Dezembro 1905, tendo sido fundada em Dezembro do mesmo ano em New York City, a "Intercollegiate Athletic Association of the United States", que a partir de 1910 passou a ter a designação de "National Collegiate Athletic Association" (NCAA). Hoje, a estrutura central da NCAA tem sede em Indianapolis - Indiana, e funciona com um quadro humano de apoio de mais de 300 pessoas. Durante vários anos, a NCAA não foi mais do que um "grupo de discussão" no âmbito da estandardização - "rules-making" - dos processos de coordenação e conjugação do trabalho. Em 1921, foi realizado o primeiro campeonato nacional da
NCAA em atletismo. A partir de então, novas regras e novos campeonatos foram institucionalizados. De acordo com Berryman (1975) a filosofia dum sistema de competição organizado para pré adolescentes, foi posto em causa pelo sistema educativo nos anos trinta, tendo muitos colégios abandonado a organização de quadros competitivos formais. Em consequência, o livre associativismo composto fundamentalmente por pais e encarregados de educação responsabilizou-se pelo sistema de competições escolares. A partir de finais dos anos trinta, foi organizado um sistema "voluntário" de "Ligas Infantis" com uma estrutura fortemente profissionalizada cuja missão era organizar, numa perspectiva de "gestão de negócio", competições para crianças com menos de 12 anos. É evidente que um sistema deste tipo conduziu aos excessos, hoje, sobejamente conhecidos. Todo o sistema de Gestão do Desporto nos EUA esteve, desde sempre, ligado à necessidade de "fazer dinheiro", pelo que, muitas vezes, os fins justificaram os meios. Por isso, não é de estranhar que, de acordo com Zeigler, E. (1987), na década de sessenta, ainda não existissem, estudos significativos, relativos à gestão e administração do desporto. O autor referido, publicou em 1959 "Administration of Physical Education and Athletics" e, posteriormente em 1975, "Administrative Theory and Practice in Physical Education and Athletics". Em 1971 a "American Association for Health, Physical Education and Recreation" já tinha, também, publicado, "Administration of Athletics in Colleges and Universities". Do lado americano, estas são as primeiras referências a mencionar.

\subsection{Europa}

No que diz respeito à Europa, houve acerca da Gestão do Desporto uma atitude mais sociológica e "jurisdicizada" ou até do domínio da economia política (Pires, G., 1989). Em conformidade, os primeiros trabalhos tendo em atenção a organização política da Educação Física e Desporto datam já da segunda metade deste século em que os autores de referência, em nossa opinião, podem ser, entre outros, Jean Dumazedier (1950) com a obra "Regards Neufs sur le Sport", George Magname (1964) e a obra "Sociologie du Sport Situation du 
Loisir Sportif dans la Culture Contemporaine”, Jean Meynaud (1966) com "Sport et Politique" e, Berthaud, G. \& Brohm J.M. \& Gantheret, F. \& Laguillaumie, P. (1972) com a obra colectiva "Sport, Culture et Repression", Bernard Jeu (1972) com "Le Sport, la Mort, la Violence". Este último autor procurou definir os conceitos, as estruturas e os modelos, em relação ao processo desportivo. $\mathrm{O}$ importante desta obra é o facto de, pela primeira vez, partindo da necessidade da "exigência de racionalidade" o autor falar em "definir políticas desportivas", idealizando um conceito com uma dimensão em que procura captar a globalidade do fenómeno. Simultaneamente na Suiça, François Pidoux (1972) publicou "Vers une Politique de Promotion Sportive”. O Finlandês Pekka Kiviaho (1973) publicou, através da Universidade de Jyväskylä, o título "Sport Organizations and the Strutcture of Society”. Em 11 de Março de 1973, a culminar todo um trabalho coordenado por Benito Castejon Paz, foi divulgado pelo Conselho da Europa, a obra "La Rationalization des Choix en Matiére de Politique Sportive”. Entretanto, o grande salto da pedagogia, da economia política e da própria sociologia para a administração dá-se em 1975 através do Comité Internacional Olímpico, ao editar uma obra intitulada "Problemes d'Organisation et d'Administration du Sport, onde aparecem nomes credenciados no domínio da pedagogia do desporto como era o de J. M. Cagical.

\subsection{Portugal}

Em Portugal, a obra paradigmática que melhor referencia a necessidade do Estado intervir administrativamente no desporto é a de Eurico Serra (1939) intitulada "Desporto Educação Física e Estado". Dizia o autor: "O Chefe do Governo anunciou já que de há muito se lhe afigura necessária qualquer intervenção para suprir o que de outro modo não poder ser feito, para coordenar o que andasse disperso, para subordinar certos individualismos inevitáveis ao alto interesse de todos. [...] A doutrina do Estado não é totalitária quanto à essência, porque o poder encerra na sua origem limites de ordem espiritual e moral" Serra, 1939: 50). Em 1967 numa perspectiva ideológica diametralmente oposta José Esteves, publica “O
Desporto e as Estruturas Sociais". Sob a coordenação de Prostes da Fonseca foi publicado em 1968 "Planeamento da Acção Educativa", editado pelo Ministério da Educação Nacional ao qual fica também ligado esse nome fundamental da administração pública portuguesa que foi José Maria Noronha Feio. Manuel Sérgio (1974) na obra "Para uma Renovação do Desporto Nacional" dá abertura à discussão política e administrativa da organização do desporto em Portugal, já na vigência do regime democrático. Seguem-se obras como as de Melo de Carvalho (1975) "Desporto e Revolução, Uma Política Desportiva” e a de Jorge Crespo (1976) "O Desenvolvimento do Desporto em Portugal um Acto Político”.

\subsection{Síntese}

Do exposto, é possível concluir que aquilo que consideramos ser a Gestão do Desporto não nasceu de geração espontânea, já que é o resultado dum processo de evolução longo, do qual, agora, começam a existir as primeiras sínteses reflexivas. Embora por vias distintas, uma norte-americana centrada na base do desporto universitário das ligas e da gestão de negócios e outra europeia, mais preocupada na intervenção política da administração pública e da consequente generalização da prática desportiva através do "Desporto para Todos", o que é facto é que, a actual Gestão do Desporto encontra as suas raízes na pedagogia do desporto em geral e nas acções de lazer e recreação em particular. Nos EUA, na organização das praticas desportivas de competição escolar. Na Europa, nas actividades de lazer e competição organizadas pelos clubes sociais, promovidas e apoiadas pelo próprio Estado. Na sociedade globalizada que estamos a viver qualquer dos modelos está a ser cada vez mais comercializado pela indústria do entretenimento que vai, no futuro condicionar o processo de desenvolvimento do desporto e, em consequência a gestão das suas práticas.

\section{ORGANIZAÇÕES}

No que diz respeito ao surgimento de organizações relacionadas com a problemática da Gestão do Desporto, na América do Norte a "North América Society for Sport Management" foi fundada em 
1985/86 por académicos tanto dos EUA como do Canadá. Na Europa, a European Association for Sport Management, existe desde 1993. Ambas as Associações têm vindo a realizar, respectivamente, os seus congressos anuais e produzem, cada uma, uma revista com uma regularidade semestral. A "Journal of Sport Management" que começou a ser publicada em 1987 para a América do Norte e a "European Journal for Sport Management", publicada desde 1994, para a Europa. Embora a associação americana seja de pessoas, a europeia é de pessoas e organizações nacionais. Assim, nesta associação, estão filiadas diversas associações nacionais, entre as quais a Associação Portuguesa de Gestão de Desporto, fundada em 22 de Janeiro de 1996. Na Austrália, Nova Zelândia, Japão e outros países da região existe uma situação semelhante. Todas estas associações formam uma associação mundial, a "International Aliance for Sport Management", de características informais, que se reúne em congresso mundial de quatro em quatro anos. De facto, a dinâmica social, criada através da institucionalização de organizações de cariz científico e profissional, também nos parece ser uma forte alavanca de desenvolvimento, para esta nova área de conhecimento.

\section{INVESTIGAÇÃO}

A investigação parece ser outro aspecto de consenso entre os diversos autores, no que diz respeito ao processo de institucionalização da Gestão do Desporto. É evidente que a investigação não surge de geração espontânea. De facto, a primeira investigação em Gestão do Desporto foi realizada no âmbito da própria Educação Física. Nem outra coisa seria de esperar, já que foi no âmbito da Educação Física que surgiu, duma maneira natural, a investigação na área das Ciências do Desporto. Tevor Slack. (1998) da Universidade de Alberta no Canadá, um dos mais prestigiados investigadores no domínio da Gestão do Desporto afirma que "... much of the work we have produce has been restricted to studies of physical education or athletic programs, and to a lesser extent professional sport organizations and national sport bodies." Segundo o autor, nos primeiros 20 números do "Journal of Sport Management", os trabalhos publicados com uma perspectiva empírica, $65 \%$ relacionavam-se com Educação Física ou "athletic programs", 12.5\% com organizações desportivas, $10 \%$ com fitness clubes, e $7 \%$ com "professional sport franchises". É evidente que há que considerar a tradição que a este respeito reside, em muitas circunstâncias, na própria Educação Física. Por exemplo, em 1971 a "American Association for Health, Physical Education and Recreation" proclamava que "the responsability for directing and managing intercollgiate athletics in the colleges and universities has passed through several identifiable phases since the inception of competitive school sports. [...] The director of physical education has the ultimate responsability for the entire athletic program." Portanto, como referimos anteriormente, na América do Norte, a tradição da Gestão do Desporto, vem do trabalho desenvolvido no quadro dos programas desportivos nos colégios e universidades.

Na Europa Ocidental, a partir dos anos sessenta, foram desenvolvidos programas de promoção do desporto que obrigaram a uma significativa capacidade de gestão dos grandes movimentos de massas, então iniciados, bem como, em consequência a produção de trabalhos de investigação no âmbito das políticas desportivas e dos padrões de participação nos diversos países. $\mathrm{Na}$ realidade, o conceito de "Desporto para Todos", sobejamente conhecido, deu origem a processos de gestão desde as grandes decisões estratégicas, realizadas a nível dos Governos, até ao planeamento operacional dos diversos organismos públicos ou privados que acabaram por ter de as implementar. No âmbito do Conselho da Europa, foi iniciado um trabalho em 1968, por um grupo de planificação, encarregado de "definir o conteúdo da ideia de "Desporto para Todos" (Actes de la Conferences des Ministres Europeens Responsables du Sport, 1975). Este trabalho deu origem a que o Comité dos Ministros, em Setembro de 1976, tenha adoptado a resolução "(76) 41" relativa aos princípios de uma política de "Desporto para Todos", tal como foram definidos na Conferência dos Ministros responsáveis pelo desporto realizada em Bruxelas no ano anterior. Estava, assim, lançada a "Carta Europeia de Desporto para Todos" (Rapport sur les Activités du Conseil de l'Europe,1977) que, ao propor que se 
criassem as condições para que a generalidade da população tivesse acesso à prática desportiva, estava, simultaneamente, a provocar que se utilizassem processos de gestão do desporto mais sofisticados o que por sua vez desencadeou projectos de investigação que funcionaram como "processos de tomada de decisão".

Portanto, não é de admirar que tanto na América do Norte como na Europa, a investigação em Gestão do Desporto ainda mantenha laços muito estreitos com o que se passa no mundo da educação em geral e da Educação Física em particular e toda a dinâmica subjacente às actividades interpessoais e de decisão porque esta é, de facto, a tecnologia que tem de ser gerida. Por outro lado, é compreensível que a produção em matéria de Gestão do Desporto ainda não tenha atingido um volume, por exemplo, comparável ao realizado em fisiologia, pedagogia ou, até, biomecânica, porque se está no início dum processo com uma idiossincrasia própria que surge precisamente da interface do cruzamento da gestão com o desporto contextualizado a um dado ambiente. De resto, veja-se que muito embora a situação esteja a mudar, temos de considerar que também no mundo da própria gestão em geral, a investigação empírica não está muito desenvolvida (Shenhav, Yehouda, 1999). Nestas circunstâncias, em nossa opinião, não podemos ser "mais papistas do que o Papa" e esperar que no mundo da Gestão do Desporto as coisas sejam muito diferentes daquelas que acontecem na própria gestão. É necessário dar tempo ao tempo e não querer que resultados que outros obtiveram em duzentos ou mais anos de profissão sejam, por nós, obtidos em pouco mais de vinte anos.

No entanto, é bom que se refira que a partir do início dos anos noventa podem ser encontradas perspectivas diferentes de entender o fenómeno de gestão do desporto, não a partir do desenvolvimento dos currículos de Educação Física, mas a partir da própria organização das práticas desportivas no âmbito dos diversos sistemas desportivos. Tanto na América do Norte Parkhouse, L., \& Ulrich, O. (1979) Chelladurai, P. (1985), Paton, G. (1987), Rail, G. (1988) Zeigler, F. (1989), como na Europa, Chazaud, P. (1983) Pires, G. (1989) começaram a ser publicados trabalhos em que a estratégia principal começou a situar-se na necessidade de sistematizar o conhecimento tradicional das ciências do desporto, com os ensinamentos que chegavam do domínio da administração e da gestão, tanto na vertente que conduz à problemática da promoção social como à da gestão de negócios.

Os anos noventa ficam também ligados ao arranque dos congressos de gestão do desporto organizados do lado americano pela a "North América Society for Sport Management" e do lado europeu pela European Association for Sport Management.

\section{OPORTUNIDADES PROFISSIONAIS}

Aquilo a que se pode designar por gestão do desporto tem sido investigado por diversos autores sendo hoje já possível começar a desenhar os contornos daquilo que os gestores de desporto fazem. Lambrecht, K. (1987), através dum estudo em que consultou 264 gestores desportivos de organizações com diferentes dimensões determinou áreas de competências que tinham inclusivamente a ver com a dimensão das organizações.

Kjeldsen, E. (1990), a partir de 69 questionários, correspondentes à taxa de retorno de $54.8 \%$, de técnicos com formação inicial em gestão do desporto, procurou saber qual o perfil dos postos de trabalho bem como as expectativas de carreira, de forma a que a posteriormente a nível académico os estudantes pudessem ser informados acerca daquilo que se estava a passar no campo profissional. Parks, J (1991), reforça a necessidade de saber a colocação e o estatuto profissional daqueles que trabalham no domínio da gestão do desporto no sentido de, posteriormente, melhor organizar a formação inicial. Pelo que foram enviados 167 questionários (taxa de resposta de $63.0 \%$ ). Os resultados permitiram concluir acerca do nível de formação, estratégia de colocação, posição e salários. $\mathrm{O}$ autor conclui pela necessidade de se continuarem a desenvolver trabalhos do tipo "levantamento do perfil do posto profissional no domínio da gestão, mas numa perspectiva interdiciplinar.

De facto, o desporto apresenta-se como um sector de intervenção profissional diversificada com enormes potencialidades, não só no âmbito da economia tradicional bem como no da emergente economia social. Em conformidade, o desporto tem vindo a 
criar um crescente número de oportunidades de emprego com tendência para o crescimento. Dos diversos trabalhos realizados é desde já possível concluir que existem a nível dos diversos países:

- Estruturas estatais descentralizadas segundo uma dinâmica territorial mais ou menos orgânica;

- Estruturas profissionais de acolhimento tanto a nível internacional como nacional;

- Estruturas de poder local com capacidade de intervenção no mundo do desporto;

- Um crescente número de federações desportivas internacionais, nacionais e regionais;

- Um número indeterminável de associações de modalidades;

- Milhares de clubes, grandes, médios e pequenos;

- Ginásios e centros de "fitness";

- Empresas de serviços desportivos;

- Empresas de marketing e publicidade interessadas em integrarem a ideia e o produto desporto nos seus projectos;

- Grandes e médias empresas a considerarem o desporto nas suas políticas de recursos humanos;

- Milhares de instalações desportivas de diversos tipos que tem de ser geridas por profissionais com formação especializada,

podemos avaliar as possibilidades que, quer directa quer indirectamente o desporto está a abrir.

É de notar que as instituições atrás referidas abriram as portas à participação dum significativo número de pessoas para intervirem no âmbito da gestão do desporto, e, em simultâneo, também foram criando postos de trabalho de perfil pouco esclarecido mas que constituíram o primeiro passo para a institucionalização de carreiras profissionais no âmbito da gestão do desporto. Em conformidade, é hoje possível identificar diversas postos de trabalho na área da gestão do desporto, tais como, entre outros: Directores técnicos; Secretários técnicos; Directores gerais; Técnicos de pelouros desportivos de autarquias; Directores de instalações; Gestores de eventos desportivos; Gestores de produto; Gestores de empresas e de outras organizações ou entidades privadas e públicas; Directores comerciais; Gestores de recursos humanos; Gestores da área de marketing; Consultores; Investigadores.
Muito embora nem as oportunidades de trabalho, nem os perfis profissionais estejam bem definidos, estamos em crer que não podemos entrar num processo de contemplação do sistema desportivo aguardando que tudo fique esclarecido antes de se tomar qualquer decisão. Pelo contrário, defendemos que é necessária uma atitude proactiva, quer dizer, como não conseguimos prever o futuro no mundo de mudança constante em que vivemos, só nos resta fazê-lo acontecer. Sabemos o futuro que queremos construir, pelo que, para nós, é clara a necessidade de existir uma especialização generalista em matéria de gestão do desporto, fortemente contextualizada aos diversos ambientes onde se processam actividades desportivas, que respondam, duma forma pragmática, às necessidades que em matéria de desporto, constantemente estão a surgir no sistema social. No entanto, para que isto seja possível, é necessário, em simultâneo, esclarecer, por um lado, aquilo que se entende por gestão do desporto e, por outro, o perfil de formação necessário ao exercício das funções.

\section{FORMAÇÃO EM GESTÃO DO DESPORTO}

Desde que o primeiro programa de Gestão do Desporto arrancou em 1968 na Ohio University nos EUA (Parkhouse, Bonnie, 1996) este processo nunca mais parou. Hoje existem, só nos EUA, mais de 200 instituições universitárias a oferecerem cursos de Gestão do Desporto e cerca de 50 no âmbito dos diversos países europeus. No que diz respeito a Portugal a Faculdade de Motricidade Humana foi a primeira a iniciar este processo no início dos anos oitenta, tendo actualmente uma licenciatura em Gestão do Desporto no quadro epistemológico das Ciências do Desporto. Desde então outras universidades, tanto públicas como privadas, iniciaram também o ensino de Gestão do Desporto, existindo, com diferentes perfis de formação quatro cursos (formação inicial) institucionalizados (Universidade Técnica de Lisboa, Universidade da Beira Interior, Universidade da Madeira, Instituto Superior da Maia) e um outro, na Universidade de Coimbra a arrancar. Para além destes cursos, tanto a Universidade Técnica de Lisboa como a Universidade do Porto estão empenhadas na realização de Mestrados de Gestão do Desporto e até têm vindo a colaborar neste domínio. 
A pergunta que se coloca neste momento é a de sabermos qual a formação inicial necessária para a intervenção no mundo do desporto na área da gestão? É claro, a nível mundial, que a comunidade académica necessita repensar constantemente todo o processo de ensino da gestão do desporto, de forma a assegurar que os alunos estão a ser devidamente preparados para enfrentarem os desafios do futuro. Desta premissa, resulta um conjunto de questões que é necessário, em cada momento encontrar as respostas necessárias a cada situação.

As questões a que nos referíamos são as seguintes:

- Quais as grandes modificações que, previsivelmente, ocorrerão no domínio da organização do desporto, nos próximos anos, para as quais é necessário preparar respostas?

- Porque é que as referidas transformações fazem com que a gestão seja, cada vez mais e em grande medida a resposta significante?

- Quais as competências específicas no âmbito da gestão que podem ser objecto duma transferência imediata e, porventura, directa para o domínio do desporto?

- Como é que as competências referidas deverão ser contextualizadas (espiritualizadas) ao mundo do desporto?

- Devem os currículos universitários liderar ou seguir aquilo que se passa nos sistemas desportivos?

- Em que medida deverão os currículos articular o domínio do desenvolvimento de conhecimentos com o da aprendizagem de competências?

- Em que domínios podem ou devem interagir as universidades e o sistema desportivo, no âmbito do ensino da Gestão do Desporto?

- Que qualificações e oportunidades profissionais decorrem da formação em Gestão do Desporto?

- Qual é o desenho curricular mais apropriado para responder à formação inicial em Gestão do Desporto?

É evidente que as respostas a estas questões têm de ser encontradas no âmbito das diversas necessidades sociais que, em matéria de gestão, o desenvolvimento do desporto, a nível mundial, está a desencadear. De acordo com Karen Daylchuck
(1999), numa pesquisa entre diversas instituições a nível mundial, as oportunidades de oferta de emprego no âmbito do desporto, nos próximos dez anos, vão evoluir de acordo com os seguintes itens:

1) Turismo;

2) Empreendimentos;

3) Gestão de eventos;

4) Negócios;

5) Especialistas.

Fica claro da investigação referida que é necessária uma especialização em Gestão do Desporto, sendo de prever, num futuro próximo, a necessidade de existirem, em áreas como o desporto, especialistas que respondam, com eficiência, às rápidas mudanças sociais. De facto, tem-se constatado que as licenciaturas em Educação Física e/ou Ciências do Desporto já não respondem, como foram capazes de o fazer no passado, às necessidades actuais do processo de desenvolvimento do desporto, nos diversos países do mundo.

Portanto, a pergunta que se coloca neste momento é a de sabermos qual a formação inicial necessária para uma intervenção eficaz, no âmbito da gestão, no domínio do desporto?

É evidente que é necessário encontrar critérios de credibilidade sob pena do enorme esforço conduzido pelas mais diversas instituições poder ser posto em causa. Em conformidade é necessário responder às seguintes questões:

- Qual a intenção subjacente ao desenho do currículo; - Qual o (s) método (s) pedagógicos a implementar? - Qual o material didáctico a ser utilizado?

- Qual o controlo a exercer no sentido do programa não perder a sua coerência;

- Quais as experiências e trabalhos práticos a implementar?

- Qual a dinâmica a implementar no que diz respeito à sua adaptabilidade ao Sistema Desportivo?

- Qual a estratégia de promoção do curso no futuro?

Foi o que aconteceu através de documentos produzidos por duas instituições de enorme prestígio e credibilidade a nível mundial. Este documentos, em nossa opinião, marcam a década 
de noventa naquilo que diz respeito à formação inicial e pós graduada em Gestão do Desporto. O primeiro é o "Standards for Curriculum and Voluntary Accreditation of Sport Mangement Education Programs", um documento conjunto da NASPE (North America Society for Physical Education e da NASSM (North America Society for Sport Management) editado em 1993. Nele foram estabelecidos os critérios mínimos para um currículo de Gestão do Desporto poder funcionar, não só no que diz respeito às áreas burocráticas e administrativas como científicas. O segundo documento, foi produzido a nível do Sport Management Committee da European Network of Sport Sciences in Higher Education e editado em 1995. Nele foram estabelecidos os critérios mínimos respectivamente para atribuir os diplomas de licenciatura e de mestrado a nível das universidades aderentes.

De acordo com Bonnie Parkhouse (1996) os aspectos fundamentais que um programa de gestão do desporto deve conter são os seguintes: Domínio das actividades desportivas (behavioral dimensions in sport); Gestão e competências organizacionais em desporto (management and organizational skills in sport); Ética; Marketing; Comunicação; Finanças; Economia do desporto; Direito do desporto; Política desportiva; Experiência de terreno.

Mais recentemente, Karen Daylchuck (1999), enfatiza que os programas de gestão do desporto, devem evoluir nos próximos anos, em termos estratégicos tendo em atenção quatro características fundamentais: Envolvimento com as faculdades de economia e gestão; Incrementar diversidade e especialização; Enfatizar os aspectos internacionais e globais; Melhorar a capacidade empreendedora. Em conformidade, os currículos deverão enfatizar as seguintes áreas do conhecimento: Marketing; Turismo; Recursos Humanos; Tecnologias da informação; Relações internacionais; Planeamento estratégico; Gestão de negócios.

\section{GESTÃO DO DESPORTO}

Muito embora recusemos qualquer sentimento xenófobo, - já que a ciência e o conhecimento se constroem no trabalho de interface dos diversos especialistas -, somos de opinião que os licenciados em desporto (gestão desportiva) têm um espaço científico de actuação, com um paradigma próprio de intervenção profissional, sem necessidade de subordinação epistemológica a outras especialidades de conhecimento.

Gerir um hospital, uma fábrica ou uma empresa de serviços de limpeza, não é a mesma coisa que gerir uma federação desportiva. Quem disser o contrário está completamente à parte daquilo que se passa no mundo do desporto. Querer encontrar invariantes que se apliquem uniformemente, numa acepção cartesiana e tayloriana do homem e das organizações, às mais diversas situações, sem atender às dinâmicas específicas de cada actividade social, é fazer um exercício de mera inutilidade especulativa. Entre, por exemplo, o marketing comercial e o social existem diferenças significativas. Entre o "sponsoring" desportivo e o musical, identificam-se aspectos que os afastam radicalmente. A palavra marketing está lá em todas as situações, só que com sentidos e aplicações diferentes. Não é a mesma "chave de parafusos" que aperta qualquer parafuso, nem qualquer parafuso serve para qualquer aplicação, muito embora se utilizem para funções diferentes diversas "chaves" e parafusos. Cada ferramenta tem a sua função e dentro dessa função, pode ser utilizada de diversas maneiras, todas elas correctas, em função das circunstâncias e dos circunstancialismos em que estiver a ser utilizada. As organizações desportivas numa relação biunívoca podem estabelecer relações de mútua troca de ideias e aprendizagem com todas as outras. O que já não nos parece tão evidente é que as organizações desportivas abdiquem dos seus próprios paradigmas organizacionais, para seguirem, em regime de exclusividade, paradigmas alheios, desvirtuando uma dinâmica que encontra as suas raízes na antiga Grécia, já que, em termos meramente operacionais, foi ali o berço da gestão do desporto moderno. Não se gere o vácuo, gerem-se pessoas, organizações e sistemas com características, objectivos, culturas e padrões de comportamento próprios que têm de ser conhecidos e considerados, para depois se poder agir (gerir) em conformidade, através da utilização das tecnologias apropriadas. Por isso, as escolhas que, em cada momento, são realizadas acontecem porque existem opções que se tivessem sido realizadas por outra pessoa seriam, necessariamente, diferentes. Só 
por humor, se pode admitir, como o faz Trevor Slack (1998) que é suficiente ler um jornal desportivo para se adquirir uma cultura desportiva. No entanto, a gestão do desporto em sentido geral é um espaço aberto à intervenção das mais diversas especialidades, muitas delas conseguidas a partir da própria Gestão do Desporto. Não estamos em crer que nenhuma escola se possa arvorar em detentora de todas as soluções que respondam a todos os problemas gerenciais que o mundo do desporto está a levantar. Tanto o desporto como a sua gestão são processos em plena evolução, pelo que ninguém pode pretender ter o monopólio absoluto sobre este enorme espaço de intervenção social. Por isso, ao considerarmos o conceito de gestão do desporto temos de o fazer tendo em atenção seis questões fundamentais: (1) Polissemia; (2) Dimensão híbrida; (3) Tecnologia específica; (4) Contextualização; (5) Nível de intervenção; (6) Âmbito de intervenção.

\subsection{Polissemia}

A palavra gestão é uma palavra polissémica, quer dizer, tem a qualidade de poder assumir vários sentidos. Por exemplo, um gestor financeiro poderá ter alguma dificuldade em aceitar que existe gestão no desporto, tal como um gestor desportivo terá dificuldade em perceber que a gestão pode ser reduzida ao simples domínio das aplicações financeiras. A palavra gestão assume diferentes significados para diferentes grupos sociais, podendo mesmo haver gestores, como já referimos, que trabalham no domínio do desporto sem que com isso sejam gestores de desporto. Portanto, nesta fase em que o desporto moderno caminha para a sua maturidade, não é exagerado dizer que estamos no domínio duma nova gestão que pode assumir as mais variadas formas de intervenção, para aqueles que estão encarregues de unidades ou sub unidades dum dado sistema organizacional e nele actuam através da manipulação duma tecnologia específica o desporto -, adaptada a um determinado contexto. Recordamos, ainda, as palavras de Mintzberg quando nos diz que "com os mestrados em gestão, criou-se uma neo aristocracia gestora, de mercenários, sem ligação a nenhuma empresa ou projecto, que saltam para lugares cimeiros sem passar pelos intermédios. Na história mundial, provavelmente, $99.99 \%$ dos gestores nunca receberam formação para serem gestores. Foram-no porque tinham qualidades inatas." (in: Os Melhores MBAs do Mundo, "Fortuna", n 5, Agosto de 1992). Mais recentemente este académico em entrevista à revista Fast Company (Nov, 2000) afirma que os mestrados estão a treinar as pessoas erradas, de maneira errada, para funções erradas. Isto porque a gestão para ter significado terá sempre de ser contextualizada a determinado ambiente social.

\subsection{Contextualização}

A gestão do desporto, nos problemas que é suposto resolver no dia a dia da vida das organizações, tem vindo a provocar uma aproximação das ideias políticas, estratégicas e pedagógicas, que desde sempre, duma forma mais ou menos implícita, orientaram a vida do desporto em geral e das organizações desportivas em particular, da operacionalização das próprias práticas desportivas, de tal maneira que gerir, em muitas circunstâncias, cada vez mais, está a ser agir. Quer dizer, "a gestão do desporto desceu à terra" na medida em que se está a ocupar cada vez mais das questões concretas do seu desenvolvimento.

No mundo do desporto, apesar de se aplicarem todo um conjunto de conhecimentos relativos à gestão, estes conhecimentos só adquirem significado se forem contextualizados ao ambiente onde estão a ser aplicados. Quer dizer, não chega aplicar as funções da gestão - planear, liderar, coordenar e controlar. É necessário conhecer o ambiente cultural, económico, social, político e tecnológico onde elas estão a ser aplicadas. Só assim a gestão ganha sentido e, só assim, é possível reivindicar um estatuto próprio. Portanto, para nós, não existe mágica na gestão. Quer dizer que não há nenhuma gestão que em termos absolutos seja uma mezinha que tudo pode resolver dentro do quadro do desporto. Mais do que objectivos e metas, recursos humanos e materiais, muito mais do que conceitos, técnicas e procedimentos mais ou menos quantitativos ou, mais ou menos, elaborados, a gestão, para ser efectiva, requer, acima de tudo, contexto, pelo que está em causa é a capacidade do gestor ser capaz de analisar e decidir no quadro desse contexto. Por isso, uma coisa é gerir organizações desportivas - clubes 
sociais ou comerciais, federações e associações, desporto escolar - naquilo que diz respeito ao desenvolvimento das suas práticas, outra é, por exemplo, a gestão financeira por exemplo das novéis sociedades desportivas.

O contexto determina que se giram recursos humanos, materiais e financeiros em função dum dado quadro cultural e dos objectivos a atingir que se devem coadunar com a vocação (aquilo que a organização tem de fazer) e a missão (a maneira especial como a organização cumpre a sua vocação) duma dada organização, quer dizer, têm de estar de acordo com uma dada filosofia de acção que configura uma determinada identidade cultural.

\subsection{Híbrido Cultural}

É fundamental referir que a gestão do desporto é um híbrido cultural, já que advém do cruzamento de várias ciências. Por isso, não pode ser analisada nem compreendida e avaliada, a não ser considerando todas as contribuições técnicas científicas, sociais e pedagógicas do quadro social específico em que está a ser aplicada. Challadurai, P. (1992) ao discorrer sobre o conceito de gestão do desporto, coloca desde logo, por um lado, problemas de especialização de algumas áreas no âmbito da gestão do desporto, mas, por outro, conclui que ainda não existe uma capacidade absoluta para diferenciar áreas, pelo que é melhor juntar forças no sentido de ter perfis profissionais no domínio da gestão mais consistentes. Em segundo lugar, levanta problemas de inter-relação com outras áreas do conhecimento no domínio, por exemplo, da psicologia, da sociologia e de outras, que por terem preconceitos em relação à área da gestão do desporto requerem da nossa parte um cuidado especial, já que por vezes consideram a nossa área de conhecimento como sendo um território pertença deles. Challadurai com a sabedoria de alguém que é um dos iniciadores desta área do conhecimento, aconselha uma cooperação muito íntima entre os gestores de desporto e os especialistas de outras disciplinas. Tal como nos diz Mintzberg (1992) "gestor é uma pessoa encarregada de uma organização ou duma sub unidade dessa organização". Para ele, tanto é gestor o primeiro ministro como o treinador de uma equipa desportiva, na medida em que cada gestor no fundo é um técnico que gere um determinada tecnologia que conhece e domina.

\subsection{Tecnologia}

Dos postulados anteriores decorre que tem de existir uma perfeita identificação daquele que gere com aquilo que está a ser gerido. A tecnologia dum gestor numa instituição bancária ao aconselhar aplicações financeiras aos seus clientes é completamente diferente daquela que é usada pelo director técnico dum clube ao aconselhar os pais dum jovem, no que diz respeito à prática desportiva do seu filho. Isto parece-nos uma evidência que dispensa qualquer prova. No entanto, não queremos ficar por aqui. Para passar dos dados à teoria há necessidade de imaginação criadora que, na maioria das vezes resulta do conflito de ideias de esquemas de referência, de culturas dissemelhantes ou antagónicas.

Gerem-se tecnologias em determinados ambientes específicos. Em conformidade, o "toque especial", da Gestão do Desporto, quer dizer, a sua originalidade tem de ser encontrada num conjunto de disciplinas que tenham a ver, sob o ponto de vista biológico, sociológico, psicológico e cultural com o mundo do desporto. De facto, temos de gerir, quer dizer, saber utilizar os instrumentos da gestão, aplicados a um determinado conhecimento tecnológico, o desporto. Esta gestão pode ser considerada dentro duma dada organização tendo em atenção a sua estruturação horizontal ou vertical. No primeiro caso estamos a considerar o âmbito da gestão, no segundo o nível.

\subsection{Nível de Intervenção}

Uma organização pode ser analisada segundo um eixo vertical que determina os seus níveis hierárquicos (hierarquização). Estes níveis hierárquicos obrigam a diferentes processos de gestão. De facto, a gestão realizada no vértice estratégico das organizações ou sistemas desportivos, é diferente daquela que se realiza a nível da tecnoestrutura, da logística, da linha hierárquica ou do centro operacional. Cada um destes níveis hierárquicos obriga a conhecimentos, atitudes e comportamentos específicos que têm de ser contextualizados ao mundo específico do desporto que estiver a ser considerado. A autonomia não só do ponto de vista quantitativo 
como qualitativo, para tomar decisões varia, em cada uma das sub estruturas indicadas. Em cada uma delas existe um processo de gestão em que a capacidade de tomar decisões pode ser nenhuma ou toda. No primeiro extremo (nenhuma) fica-se no domínio da gestão das normas e dos regulamentos. Nesta situação gere-se um contexto eminentemente tecnológico e fechado. No segundo extremo (toda) entra-se no domínio da gestão estratégica, dependendo esta circunstância do lugar que se ocupa no eixo vertical do organograma da organização. O que interessa aqui reter é que, por exemplo, enquanto que o presidente dum clube está no vértice estratégico da organização e, por isso, as suas decisões devem ser estratégicas, já as decisões dos gestores da linha intermédia caracterizam-se, em termos operacionais, por aquilo a que se convencionou chamar funções da gestão ou factores de desenvolvimento. Por fim, os treinadores, em nossa opinião, são os gestores de primeira linha que têm de gerir os diversos factores de treino, quer directos quer indirectos, bem como as variáveis que facilitam e potencializam a sua gestão.

No entanto, tal como um dirigente a funcionar a nível do vértice estratégico duma organização desportiva não deve descurar as questões técnicas, também um treinador não pode ignorar as questões estratégicas do clube de modo a integrá-las na gestão que faz da equipa. Cabe à gestão intermédia, descodificar e integrar coerentemente, sempre que necessário, ambos os discursos. Sabemos ser esta uma das questões cruciais no mundo dos grandes clubes desportivos. A nível do vértice estratégico existe uma visão acerca da vida económica e financeira do clube a médio e longo prazos, só que depois não existe capacidade para idealizar a correspondente estratégia desportiva, principalmente naquilo que tem a ver com a gestão do próprio conhecimento no que diz respeito aos recursos materiais humanos e informacionais bem como aos projectos e actividades a desenvolver. De facto, a gestão duma equipa profissional de futebol obriga à manipulação de variáveis diferentes daquelas que caracterizam a gestão estratégica realizada pelo presidente duma sociedade desportiva. É evidente que, sem contar com as linhas hierárquicas intermédias, o sucesso da equipa da sociedade e / ou do clube, depende significativamente da capacidade de comunicação entre o vértice estratégico e o centro operacional. Cada uma destas estruturas desenvolve discursos diferentes, pelo que cada uma delas tem de ser capaz de descodificar o discurso da outra ou então arranjar quem o faça. Estamos recordados da total incapacidade de comunicação entre de Santana Lopes e o técnico da equipa principal de futebol Carlos Queiróz. Esta incapacidade traduziu-se na ineficiência e eficácia da equipa de futebol profissional e no afastamento do treinador. Como exemplo duma boa comunicação, podemos ter como exemplo o Futebol Clube do Porto em que o seu presidente tem revelado, ao longo dos últimos anos, uma enorme capacidade de comunicar, duma forma eficaz, com o seu centro operacional.

\section{6 Âmbitos de Intervenção}

Se os diversos níveis hierárquicos são determinados sempre que se desenvolve a estrutura no sentido vertical, se quisermos compreender o desenvolvimento horizontal da estrutura (departamentalização), temos de compreender que existem critérios que já não têm a ver com a hierarquia mas com a substância da função que se está a processar.

Gerir diferentes organizações desportivas, diferentes funções, ou até diferentes modalidades - de acordo com o critério de departamentalização que se quiser utilizar -, tem especificidades técnicas e metodológicas, para além de diversas subtilezas culturais, que não se compadecem com o atrevimento de qualquer curioso que, dum momento para o outro, se vê alcandorado num lugar de gestão no âmbito do desporto, sem ter qualquer capacidade ou competência para o ocupar. Isto significa que, à semelhança daquilo a que se tem vindo a passar em diversas actividades humanas, também a gestão do desporto está a especializar-se, obrigando a existir até gestores desportivos com diferentes capacidades, como tem ficado claro nas mais diversas intervenções nos vários congressos de gestão do desporto realizados, tanto a nível nacional como internacional. Só assim é possível realizar uma perfeita coordenação do trabalho, ou reciproca, ou sequencial, ou em comunidade entre as várias unidades e sub-unidades 
que devem interagir em qualquer organização no quadro do contexto das respectivas tecnologias. No entanto, o que temos visto no país, é que estes gestores intermédios (chamados directores gerais, directores de projectos ou directores de função), em múltiplas situações têm estado mais interessados em intervirem na vida do centro operacional do que em resolverem as questões de ligação entre aquele e o vértice estratégico, criando, deste modo, a retaguarda de apoio à linha de produção (as diversas equipas a participarem no respectivos quadros competitivos), a que, pelas suas funções, estariam obrigados. Faltam, em nossa opinião, estruturas intermédias que tenham consciência da sua função de interface entre o vértice estratégico das organizações e o centro operacional, para já não referirmos a tecnoestrutura e a logística. Estamos recordados da breve passagem de António Simões pelo Sport Lisboa e Benfica que, na qualidade de Director geral, não foi capaz ou não o deixaram ser a interface necessária ao funcionamento do sistema. A actual crise do Sporting Clube de Portugal, em nossa opinião tem a ver também com o mesmo problema. $\mathrm{O}$ que está a acontecer é que tanto o vértice estratégico do clube (presidente) bem como o centro operacional (treinador) estão, por assim dizer, a trabalhar sem rede e sujeitos a todas a vicissitudes dum campeonato de futebol em que só pode haver um campeão.

\section{OPORTUNIDADES FUTURAS}

Podemos antever um futuro de promissoras oportunidades. De acordo com Karen Daylchuck (1999), numa pesquisa entre diversas instituições a nível mundial, as oportunidades de oferta de emprego nos próximos dez anos vão evoluir de acordo com os seguintes itens:

- Turismo;

- Empreendimentos;

- Gestão de eventos;

- Desporto negócio;

- Especialistas.

Fica claro da investigação referida que é necessária uma especialização em gestão do desporto, sendo de prever num futuro próximo a necessidade de existirem em algumas áreas, especialistas que respondam, com eficiência, às rápidas mudanças sociais. As simples licenciaturas em educação Física e/ou Ciências do Desporto, deixaram de ser capazes de responder às necessidades actuais do processo de desenvolvimento do desporto nos vários sectores de desenvolvimento e nos diversos países do mundo. Em nossa opinião as competências específicas para intervir em cada um dos sectores indicados podem ser obtidas, com padrões de especialização de diferentes conteúdos e níveis, nas mais diversas escolas de formação, entendendo nós que nenhuma delas pode reivindicar o direito de monopólio sobre a formação em gestão para o mundo do desporto. Portanto, antevemos as mais diversas oportunidades para muita gente e não só para este ou aquele curso.

\section{CONCLUSÕES E SUGESTÕES}

A velocidade das transformações sociais faz com que a experiência e o conhecimento de há vinte anos estejam, hoje, profundamente desactualizados, sobretudo quando as pessoas não foram, pelas mais diversas razões, capazes de evoluir. Em conformidade, os sistemas desportivos nos mais diversos países do mundo têm de ser capaz de se regenerar, sob pena de estagnarem, aliás como já é de alguma maneira notório em múltiplas organizações de âmbito nacional e internacional. Abrem-se, assim, enormes possibilidades de intervenção profissional que as novas gerações interessadas no mundo do desporto, não devem deixar de aproveitar.

Para nós, o mais importante neste momento, para além de ser sempre útil realizar o levantamento dos problemas que afectam a gestão do desporto, é questionar aquilo que se anda a fazer no âmbito da gestão do desporto com repercussões no seu desenvolvimento. Isto porque, em muitas situações os vértices das organizações desportivas fecharam-se sobre si próprios, sofrem uma desregulação inexorável em relação ao tempo que acabará por destruir as próprias organizações. Repare-se por exemplo no número de anos que alguns dirigentes desportivos se mantêm à frente das organizações. $\mathrm{O}$ recorde pertence a Marc Hodler que é presidente da Federação Internacional de Ski desde 1951 e, claro, do Comité Olímpico Internacional desde 1963. Este tipo de pessoas, se em relação ao passado foram a solução, a partir dum dado momento, passou a ser o problema. 
Isto porque o conhecimento torna-se obsoleto a acção ineficaz. Em consequência, os sistemas e as organizações acabam por estagnar por falta não só de novos recursos humanos como pela desactualização daqueles que se perpetuam e multiplicam por vários lugares por anos a fio, alimentando-se das próprias organizações a que pertencem.

Em conformidade, hoje, no mundo do desporto, existe um espaço epistemológico de intervenção cuja expressão profissional se circunscreve à gestão das práticas desportivas que difere significativamente da gestão realizada em outras áreas ou sectores económicos e sociais. Se por um lado, em matéria de gestão, existem especificidades próprias que singularizam o desporto das demais actividades, por outro, dentro dessa mesma singularidade, a gestão desportiva caracteriza-se por ser uma actividade contextualizada onde numa perspectiva multicultural se gere um tecnologia, o desporto, tendo em consideração o nível e âmbito de intervenção. A gestão dos recursos humanos, em qualquer sociedade, é um instrumento estratégico de organização do futuro. Desencadear a regeneração dos diversos sistemas desportivos por esse mundo fora, através de estratégias conduzidas a montante é um desiderato que compete à sociedade civil, mas também aos próprios governos, porque, para além de, cada vez mais, estarem em jogo verbas do erário público, colocam-se também questões de organização social. Por isso, é necessária uma formação inicial em gestão do desporto, já que a formação tradicional já não responde as necessidades sociais.

Por nós, acreditamos que é possível, através de uma aliança estratégica entre organizações cuja perspectiva de futuro ultrapasse o imediatismo da pressão dos problemas de todos os dias - quer dizer que não confundem urgência com importância -, congregar ideias, projectos e esforços, de forma a alterar o rumo dos acontecimentos. Se assim for, estamos convencidos que as novas gerações de praticantes, técnicos e dirigentes que vão chegar ao mundo do desporto em busca de emprego num mundo em que o emprego está a escassear, serão capazes de promover as mudanças necessárias. Trata-se dum investimento na mudança a médio e longo prazos, quer dizer, dum desafio às instituições e às pessoas sobre o tempo, já que necessitamos de tempo de reflexão para um desporto e uma sociedade que deixaram de ter tempo para aferir o sentido dos seus próprios valores. E quando as sociedades e as instituições, através das pessoas, começam a pensar que não necessitam de nenhuns princípios nem valores, na medida em que tudo se resume ao dinheiro, ao mando, ao sexo e ao desporto, como nos diz o teólogo Hans Küng (FT, 25/09/99), de facto, é necessário desencadear uma enorme vaga de mudança que alerte as consciências das pessoas quanto à necessidade de organizarmos um futuro que não se volte contra nós próprios. Portanto, aqueles que estão nos diversos vértices políticos da sociedade, hão-de ter de decidir se querem um desporto instrumento de educação, de lazer, de cultura e de saúde e, em consequência, promotor de economia e de desenvolvimento humano, ou se, em alternativa, querem um desporto desprovido de ética, socialmente injusto, alimentado pelo ódio e a ignorância, geradores de novos ódios e de mais ignorância, sorvedouro de dinheiros públicos, sem outra utilidade que não seja a de animar massas acéfalas que outra perspectiva não têm da vida senão a de saciarem os seus mais primários instintos agonísticos através dum espectáculo desportivo de valor social, pelo menos, questionável.

As universidades, podem assumir-se como a interface desta discussão. Isto já está a acontecer de alguma maneira, na América do Norte (EUA e Canadá) através da "North America Society for Sport Management", e na Europa através da "European Association for Sport Management" que recentemente, com outras associações continentais constituíram a "International Aliance for Sport Management”. No entanto, não somos ingénuos ao ponto de pensar que este movimento internacional provocará rapidamente transformações a nível dos sistemas desportivos dos diversos países. $\mathrm{Na}$ realidade, a cooperação que acontece a nível internacional ainda não tem efeitos nos diversos sistemas desportivos, na medida em que estes, na grande maioria das vezes, são compostos por estruturas muito pesadas, pouco receptivas ao conhecimento adquirido por via académica e, sobretudo, com uma mentalidade de que é mais importante fazer do que saber fazer. No entanto, a continuar este processo, tanto a nível internacional 
como dos diversos países, as mudanças, mais cedo ou mais tarde, acabarão por acontecer, a partir do momento em que as Universidades, sejam elas quais forem, começarem a colocar no mercado de trabalho, quadros com uma mentalidade e um posicionamento em relação às questões do desporto diferentes daquelas que formaram os dirigentes educados na lógica do sistema industrial e condicionados aos processos de supercompensação dele decorrentes (Bouet, M., 1968).
Estes desafios requerem, em matéria de gestão, organização e desenvolvimento do desporto, novas atitudes e diferentes soluções, no sentido de serem criadas nova oportunidades para futuras gerações de praticantes, técnicos, dirigentes e espectadores. A não ser assim, aqui fica o aviso, as actuais gerações de dirigentes hão-de ser responsabilizadas por não terem sido capazes de promover um modelo sustentado de desenvolvimento do desporto que não comprometesse as práticas desportivas das gerações futuras.

\section{BIBLIOGRAFIA}

American Association for Health, Physical Education and Recreation (1971) Administration of Athletics in Colleges and Universities, Washington, American Association for Health, Physical Education and Recreation.
Berthaud, G. \& Brohm J.M. \& Gantheret, F. \& Laguillaumie, P. (1972) Sport, Culture et Repression, Paris, Françoi Maspero. Bouet, M. (1968) Les Motivations des Sportives, Paris, Editions Universitaires. 
Chazaud, P. ( 1983) Le Sport et as Gestion, Paris, Vigot. Chelladurai, P. (1985) Sport Management, London, Canada, Sport Dynamics.

Chelladurai, P. (1994) Sport Management: Defining a Field. In: "European Journal for Sport Management", Vol. 1 - Nr. 1, May 1994

Chelladurai, P. (1999) Human Resources Management in Sport and Recreation, Human Kinetics.

Costa, Lamartine (1979) Noções de Administração para Profissionais da Educação Física e dos Desportos, Brasília, DF Departamento de Documeentação e Divulgação.

Costa, Lamartine (1986) A Abordagem em Rede de Lazer e do Esporte para Todos: Uma tentativa de revisão epistemológica, taxonômica e organizacional do esporte e da educação física, in: Comunidade Desportiva , Rio de Janeiro, 6 v (38) Maio/ Junho. Editado em Portugal pelo Ministério da Educação e Cultura - Direcção Geral dos Desportos, col. "Desporto e Sociedade" n. ${ }^{\circ} 28$.

Crespo, Jorge (1976) O Desenvolvimento do Desporto em Portugal um Acto Político, Lisboa, ISEF.

Dumazedier, J. (1950) Regards Neufs sur le Sport, Paris Seuil. Esteves, José (1967) O Desporto e as Estruturas Sociais, Lisboa, Prelo Editora.

Fielding, F. (1991) Defining Quality: Should Educators in Sport Management Programs be Concerned About Acreditation? in: "Journal of Sport Management", n. 5. Fonseca, Prostes (1968) Planeamento da Acção Educativa, Lisboa, Ministério da Educação Nacional.

Gordon, ${ }^{a}$ et al (1988) Personal Style and Administrative Behavior in Amateur Sport Organisations, in: "Journal of Sport Management", n. 2.

Karen Daylchuck et al (1999) Sport Management as an Academic Discipline in the Next Millenium, In: Proceedings of the 7th Congress of the European Association for Sport Management. Thessaloniki, September $16-19,1999$.

Kiviaho, Pekka (1973) Sport Organizations and the Struture of Society, Finland, Department of Sociology and Planning for Physical Culture \& Research Institute of Physical Culture and Health.

Kjeldsen M. (1990) Sport Management Careers: A Desscriptive Analysis, in: "Journal of Sport Management", n. 4.

Lambrecht W. (1987) Na Analysis of the Competencies of Sport and Athletic Club Managers, in: "Journal of Sport Management", n. 1.

Lambrecht W. (1991) A Study of Curricular Preparation Needs for Sport Club Managers, in: "Journal of Sport Management", n. 5. Meynaud, Jean (1966) Sport et Politique, Paris, Payot. Olafson, a (1990) Research Dsign in Sport Management: What's Missing, What's Needes?, in: “Journal of Sport Management", n. 4.

NASPE-NASSM (1993) Standards for Curriculum and Voluntary Accreditation of Sport Management Education Programs, in: "Journal of Sport Management", n. 7.

Parkhouse, B. (1996) The Management of Sport It's Foudation and Aplication, USA, Mosby.

Parkhouse, L., \& Ulrich, O. (1979) Sport Management as a Cross Potetial Cross Discipline: A Paradigm for Theoretical Development, Scientific Inquiry, and Professional Application, in: Quest.

Paton, G. (1987) Sport Management Research: What Progress Has Been Made? Journal of Sport Management, $n^{\circ} 1$.

Paz, Castejon (1973) La Rationalization des Choix en Matiére de Politique Sportive Esquisse d'une Metodologie Les Intruments Conceptuels, Strasbourg, Conseil de L'Europe. Pidoux, François (1972) Vers une Politique de Promotion Sportive. Images du Sport en Suisse Romande, Birkhäuser Verlag Basel.

Pires, G. \& Claudino, R. (1994) Profissões do Desporto - Perfil de Competências do Treinador e Gestor Desportivo- Estudo de Mercado, Universidade Técnica de Lisboa, Faculdade de Motricidade Humana, Departamento de Ciências do Desporto, Projecto Apoiado pelo Fundo Social Europeu.

Pires, G. (1989) A Estrutura e a Política Desportivas: O Caso Português, Estudo da Intervenção do Aparelho Estatal no Sistema Desportivo Português, Lisboa, Instituto Superior de Educação Física, dissertação apresentada com vista à obtenção do grau de Doutor em Motricidade Humana.

Pires, G. (1993) A Organização Faz a Organização da Organização, in: Ludens, Lisboa, Faculdade de Motricidade Humana, Vol. 13, n 3/4, Julho-Dezembro.

Pires, G. (1994) Do Jogo ao Desporto, Para Uma Dimensão Organizacional do Conceito de Desporto. Um Projecto Pentadimensional de Geometria Variável. In. Ludens, Vol.14 $\mathrm{n}^{\circ} 1$, Jan.-Mar. 1994.

Rail, G. (1988) A Theoretical framework for the Study of Complex Sport Organisations, in: "Journal of Sport Management", n. 3.

Sanch, J. (1995) Planificacion Deportiva - Teoria Y Pràtica, Barcelona, Inde.

Sérgio, Manuel (1974) Para uma Renovação do Desporto Nacional, Lisboa, Moraes.

Serra, Eurico (1939) Desportos Educação Física e Estado, Lisboa, Bertrand.

Seurin, Pierre (1962) Étude Comparative de l' Organization de l'Education Physique et des Sports dans les Pays Occidentaux. in: "Bulletin de la F.I.E.P.".

Shenhav, Yehouda (1999) A Institucionalização da Teoria da Gestão: Um Estudo de Séries Temporais, In: "Comportamento Organizacional e Gestão", Lisboa, Instituto Superior de Psicologia Aplicada, v 5, n1.

SlacK, T. (1997) Understanding Sport Organisations - The Application of Organization Theory, Human Kineticks. Slack, Trevor (1998) Is There Anything Unique About Sport Management? In: "European Journal for Sport Management", Vol. 5 - Nr. 2, August 1998.

Slack,T. (1991) Sport Management : Some Thoughts on Future Directions, in: "Journal of Sport Management", n. 5.

Soucie, D (1994) The Emergence of Sport Management as a Professional Occupation: A North America Perspective" In:

"European Journal for Sport Management", Vol. 1 - Nr. 2, September 1994.

Steward, R., et al (1998) The Economic Parameters of Professional Sport in Australia Lessons for Sport

Administrators, In: "European Journal for Sport Management", Vol. 5 - Nr. 2, August 1998.

Tatarelli, G. ( 1986) L'Organizzazione Sportiva - Metodologie, Roma, CONI, Scuola dello Sport.

Watt, David (1998) Sport Management and Administration, London, E \& FN SPON.

Zeigler, F (1987) Sport Management: Past, Present, and Future, in: "Journal of Sport Management", n. 1.

Zeigler, F. (1989) Proposed Creed and Code of Professional Ethics for the North America Society for Sport Management", in: "Journal of Sport Management", n.3. 000. 